\title{
Skeletal muscle mitochondrial DNA content in
}

exercising humans

A. Marcuello, J. González-Alonso, J. A. L. Calbet, R. Damsgaard, M. J. López-Pérez and C. Díez-Sánchez

Journal of Applied Physiology 99:1372-1377, 2005. First published Jun 2, 2005;

doi:10.1152/japplphysiol.00289.2005

You might find this additional information useful...

This article cites 33 articles, 16 of which you can access free at:

http://jap.physiology.org/cgi/content/full/99/4/1372\#BIBL

Updated information and services including high-resolution figures, can be found at:

http://jap.physiology.org/cgi/content/full/99/4/1372

Additional material and information about Journal of Applied Physiology can be found at: http://www.the-aps.org/publications/jappl

This information is current as of September 25, 2005 .

Journal of Applied Physiology publishes original papers that deal with diverse areas of research in applied physiology, especially those papers emphasizing adaptive and integrative mechanisms. It is published 12 times a year (monthly) by the American

Physiological Society, 9650 Rockville Pike, Bethesda MD 20814-3991. Copyright (C) 2005 by the American Physiological Society. ISSN: 8750-7587, ESSN: 1522-1601. Visit our website at http://www.the-aps.org/. 


\title{
Skeletal muscle mitochondrial DNA content in exercising humans
}

\author{
A. Marcuello, ${ }^{1}$ J. González-Alonso, ${ }^{2}$ J. A. L. Calbet, ${ }^{3}$ \\ R. Damsgaard, ${ }^{2}$ M. J. López-Pérez, ${ }^{1}$ and C. Díez-Sánchez ${ }^{1}$ \\ ${ }^{1}$ Department of Biochemistry, Molecular and Cell Biology, University of Zaragoza, Zaragoza, Spain; \\ ${ }^{2}$ The Copenhagen Muscle Research Centre, Rigshospitalet, University of Copenhagen, Denmark; and \\ ${ }^{3}$ Department of Physical Education, University of Las Palmas de Gran Canaria, Canary Islands, Spain
}

Submitted 10 March 2005; accepted in final form 30 May 2005

Marcuello, A., J. González-Alonso, J. A. L. Calbet, R. Damsgaard, M. J. López-Pérez, and C. Díez-Sánchez. Skeletal muscle mitochondrial DNA content in exercising humans. J Appl Physiol 99: 1372-1377, 2005. First published June 2, 2005; doi:10.1152/japplphysiol.00289.2005.—Several weeks of intense endurance training enhances mitochondrial biogenesis in humans. Whether a single bout of exercise alters skeletal muscle mitochondrial DNA (mtDNA) content remains unexplored. Double-stranded mtDNA, estimated by slot-blot hybridization and real time PCR and expressed as mtDNA-to-nuclear DNA ratio (mtDNA/nDNA) was obtained from the vastus lateralis muscle of healthy human subjects to investigate whether skeletal muscle mtDNA changes during fatiguing and nonfatiguing prolonged moderate intensity $[2.0-2.5 \mathrm{~h} ; \sim 60 \%$ maximal oxygen consumption $\left(\dot{\mathrm{V}}_{2}\right.$ max $\left.)\right]$ and short repeated high-intensity exercise (5-8 min; $\sim 110 \% \dot{\mathrm{V}}_{2}$ max $)$. In control resting and light exercise $(2 \mathrm{~h} ; \sim 25 \%$ $\dot{\mathrm{V}}_{2}$ max $)$ studies, mtDNA/nDNA did not change. Conversely, mtDNA/nDNA declined after prolonged fatiguing exercise $(0.863 \pm$ 0.061 vs. $1.101 \pm 0.067$ at baseline; $n=14 ; P=0.005)$, remained lower after $24 \mathrm{~h}$ of recovery, and was restored after $1 \mathrm{wk}$. After nonfatiguing prolonged exercise, $\mathrm{mtDNA} / \mathrm{nDNA}$ tended to decline ( $n=10 ; P=0.083$ ) but was reduced after three repeated highintensity exercise bouts $(0.900 \pm 0.049$ vs. $1.067 \pm 0.071$ at baseline; $n=7 ; P=0.013$ ). Our findings indicate that prolonged and short repeated intense exercise can lead to significant reductions in human skeletal muscle mtDNA content, which might function as a signal stimulating mitochondrial biogenesis with exercise training.

human skeletal muscle; mtDNA content; exercise

BIOGENESIS OF THE OXIDATIVE phosphorylation system requires the concerted expression of nuclear and mitochondrial genomes. The maintenance of the mitochondrial DNA (mtDNA) genomic dose (number of mtDNA copies per cell) may play a key role in the expression of mtDNA genes because the depletion of mtDNA is associated with several pathological syndromes (for review, see Refs. 9, 33). In the case of human skeletal muscle, alterations in mtDNA expression such as point mutations, deletion, duplication, and depletion of mtDNA can severely affect its functionality (8). This is not surprising in the light of the observation that mtDNA content correlates closely with citrate synthase activity and oxygen consumption in human skeletal muscle, suggesting an interplay among gene expression, enzyme activity, and metabolism (34). In this context, exercise conditions that alter mtDNA content could ultimately impair skeletal muscle function and adaptation. Although the effects of free radicals on mitochondria are not entirely clear (1), prolonged and intense exercise is often associated with increases in skeletal muscle oxidative stress

Address for reprint requests and other correspondence: C. Díez-Sánchez, Dept. of Biochemistry, Molecular and Cell Biology, Univ. of Zaragoza, Miguel Servet 177, 50013 Zaragoza, Spain (e-mail: cardisan@unizar.es). and reactive oxygen species (ROS) production, which could damage mtDNA $(2,4,6,19,20,22,23,26,28)$. On the other hand, recent evidence suggests that prolonged endurance exercise stimulates mitochondrial biogenesis in skeletal muscle by increasing the peroxisome proliferator activated receptor coactivator $1 \alpha$, a nuclear factor critical in coordinating mitochondrial biogenesis (27). The enhanced mitochondrial content with endurance training might then be due to the repeated activation of mitochondrial biogenesis after each bout of exercise (17). Whether mtDNA content in human skeletal muscle changes with a single bout of exercise remains unknown.

The principal aim of study was to investigate the effect of prolonged moderate intensity and short high-intensity exercise on the mtDNA content of human skeletal muscle. To accomplish this purpose, we examined the changes in mtDNA-tonuclear DNA (nDNA) ratio (mtDNA/nDNA) in biopsy samples from the human vastus lateralis muscle obtained before and after cycling exercise of different intensities and durations. Our findings showed that mature mtDNA (double-stranded DNA) strands diminished as a consequence of prolonged exercise and repeated intense exercise, being fully restored a week later.

\section{MATERIALS AND METHODS}

Preparation and characterization of muscle samples. A total of 28 healthy, recreationally active or trained subjects (25 men and 3 women) participated in this investigation. They possessed a mean $( \pm \mathrm{SD})$ age of $25 \pm 4 \mathrm{yr}$, body weight of $75 \pm 9 \mathrm{~kg}$, height of $182 \pm$ $9 \mathrm{~cm}$, maximal heart rate of $192 \pm 10$ beats $/ \mathrm{min}$, and maximal oxygen uptake $\left(\mathrm{V}_{2}\right.$ max $)$ of $4.6 \pm 0.71 /$ min or $61 \pm 5 \mathrm{ml} /(\mathrm{kg} \cdot \mathrm{min})$. The subjects were fully informed of any risks and discomforts associated with the experiments before giving their informed, written consent to participate. The study conforms to the code of ethics of the World Medical Association (Declaration of Helsinki) and was approved by the Ethics Committee of Copenhagen and Frederiksberg.

This study consists of one resting (protocol 1) and four exercise protocols (protocols 2-5) carried out on a cycle ergometer: 1) supine rest for $2 \mathrm{~h}$ under thermoneutral conditions $\left.\left(\sim 20^{\circ} \mathrm{C}\right)(n=5) .2\right)$ Very-low-intensity exercise for $2 \mathrm{~h}$ under thermoneutral conditions $\left(\sim 25 \%\right.$ of $\left.\dot{\mathrm{V}}_{2 \text { max }} ; 64 \pm 24 \mathrm{~W} ; n=5\right)$. This exercise protocol entailed little physiological stress as suggested by their low heart rate $(\sim 100$ beats/min) and perceived exertion $(10 \pm 2$ Borg units; very light). 3) Moderate-intensity exercise in the heat until exhaustion $\left(2.0-2.5 \mathrm{~h} ; \sim 60 \% \dot{\mathrm{V}}_{2}\right.$ max or $210 \pm 20 \mathrm{~W}$; ambient temperature $35^{\circ} \mathrm{C} ; 40-50 \%$ relative humidity, $1-2 \mathrm{~m} / \mathrm{s}$ fan speed; $n=14$ ). In this protocol, the subjects cycled until volitional exhaustion ("fatiguing" trial) while developing significant dehydration $(\sim 4 \%$ body weight loss) and hyperthermia (core and leg muscle temperature 39.5-

The costs of publication of this article were defrayed in part by the payment of page charges. The article must therefore be hereby marked "advertisement" in accordance with 18 U.S.C. Section 1734 solely to indicate this fact. 
Table 1. Experimental protocols

\begin{tabular}{|c|c|c|c|c|c|c|c|}
\hline Experimental Protocols & $n$ & $\mathrm{VO}_{2}$ max,$\%$ & Power Output, W & $\begin{array}{c}\text { Duration, } \\
\text { min }\end{array}$ & $\begin{array}{l}\text { Environmental } \\
\text { Temperature, }{ }^{\circ} \mathrm{C}\end{array}$ & Hyperthermia & $\begin{array}{l}\text { Fatiguing } \\
\text { Exercise }\end{array}$ \\
\hline Supine rest (control) & 5 & & & 120 & 20 & - & - \\
\hline Low-intensity cycling (control) & 5 & $\sim 25$ & $64 \pm 24$ & 120 & 20 & - & - \\
\hline Moderate-intensity cycling (nonfatiguing) & 10 & $\sim 60$ & $210 \pm 20$ & $120-145$ & 35 & - & - \\
\hline Repeated high-intensity cycling & 7 & $\sim 110$ & $356 \pm 14$ & & & & \\
\hline 1st Bout & & & & 5 & 44 & + & + \\
\hline
\end{tabular}

Values are means $\pm \mathrm{SD} ; n$, no. of subjects. - , without; + , with.

$\left.40.5^{\circ} \mathrm{C}\right)$. The exercise was perceived as very, very hard at the point of exhaustion (19.4 \pm 0.2 Borg units). 4) Moderate-intensity nonfatiguing exercise in the heat (same ambient and exercise conditions as protocol $3 ; n=10$ ) but the subjects cycled while maintaining euhydration by consuming fluids and stabilizing core and muscle temperature at $38.0-38.8^{\circ} \mathrm{C}$. This exercise protocol was perceived as fairly light or somewhat hard (11-13 Borg units). 5) Repeated highintensity exercise eliciting fatigue after $5-8 \mathrm{~min}(n=7)(\sim 110 \%$ $\dot{\mathrm{V}}_{2}$ max $\left.; 356 \pm 14 \mathrm{~W}\right)$. This exercise protocol consists of three high-intensity exercise bouts, preceded by $10-15 \mathrm{~min}$ of light exercise (warm-up) and 5 min of rest, and separated by $1 \mathrm{~h}$ of rest. Bout 1: heat stress fatiguing bout; the subjects cycled until volitional fatigue while wearing a jacked perfused with water at $46^{\circ} \mathrm{C}$. Bout 2: control nonfatiguing bout; the subjects cycled for the same duration as bout 1 while exposed to an ambient temperature of $14-16^{\circ} \mathrm{C}$ and fan cooling. Bout 3: control fatiguing bout (see Table 1 summarizing the experimental protocols). In protocol 5, the subjects ingested $\sim 2$ liters of a carbohydrate-electrolyte solution (Gatorade) during resting periods to restore bodily fluid compartments and bodily energy stores. The systemic and muscle metabolic responses to prolonged and short intense exercise have previously been reported in detailed $(14,15)$.

Biopsy samples from the vastus lateralis muscle were obtained before and after each experimental condition. In the prolonged fatiguing exercise condition, additional biopsy samples were obtained after 2 and $24 \mathrm{~h}$ as well as after $1 \mathrm{wk}$ of recovery from exercise when subjects return to perform the nonfatiguing exercise bout. All samples were frozen in liquid nitrogen for $5-10 \mathrm{~s}$ and stored at $-80^{\circ} \mathrm{C}$ for later analysis. Before biochemical and DNA analysis, muscle biopsies were freeze-dried overnight at a temperature of $-40^{\circ} \mathrm{C}$ by applying a vacuum equivalent to $\leq 0.01 \mathrm{mmHg}$. The muscle samples were then dissected free from blood and visible connective tissue under a dissecting stereomicroscope in a room kept at a temperature of $20^{\circ} \mathrm{C}$ and relative humidity of $<30 \%$.

DNA extraction and molecular analysis. Total DNA from muscle was obtained by conventional methods (30) with some modifications as described elsewhere (31). To exclude single-stranded DNA, isolation of double-stranded DNA was carried out twice with phenol extraction (25). Estimation of mtDNA content is generally achieved by slot-blot hybridization (Micro-Sample Filtration Manifold, Schleicher and Schuell) and the relative values normalized by a signal given by a nuclear gene probe. We used $0.5 \mu \mathrm{g}$ of total DNA prepared from muscle samples after being denaturalized by $0.5 \mathrm{M} \mathrm{NaOH}$ and transferred to nylon filter by slot-blot (7). After prehybridization at $68^{\circ} \mathrm{C}$ in $6 \times \mathrm{SSC}, 0.1 \%$ SDS, $10 \mathrm{mg} / \mathrm{ml}$ salmon sperm DNA, $1 \mu \mathrm{g} / \mathrm{ml}$ sodium pyrophosphate, and $5 \times$ Denhardt's solution for $2 \mathrm{~h}$, filters were first hybridized with a 273-bp mitochondrial probe against the 16S mt-rRNA gene (nucleotide 1621 to 1894 of the human mtDNA sequence). After stripping at $100^{\circ} \mathrm{C}$ for $15 \mathrm{~min}$ in $0.01 \mathrm{SSC}, 1 \% \mathrm{SDS}$ and checking by autoradiography that mitochondrial probe was completely eliminated, filters were rehybridized with a 431-bp nuclear probe against the 18S n-rRNA gene (nucleotide 757 to 1188 of the gene sequence). Both probes were synthesized by PCR amplification and labeled by High Prime kit (Roche Diagnostics, Indianapolis, IN) and ${ }^{32} \mathrm{P}$-dCTP. Filters were hybridized with 500,000-1,000,000 $\mathrm{cpm} / \mathrm{ml}$ of appropriated probe in $6 \times \mathrm{SSC}$ at $68^{\circ} \mathrm{C}$. After hybridizations, filters were autoradiographed at $-70^{\circ} \mathrm{C}$ by using Hyperfilm (Amersham, Piscataway, NJ) with an intensifier screen, and autoradiograms were evaluated by a LKB laser densitometer (Ultroscan XL, LKB Produkter, Bromma, Sweden) and Gelscan XL software. 143B, a human osteosarcoma-derived cell line, has been used as a control of the correlation between the DNA loaded and the signal obtained in Southern blot analysis. We illustrate the Southern blot quantification in Fig. 1.

The mtDNA content was also measured by the real-time PCR (RT-PCR) method using an ABI Prism 7700 Sequence Detection

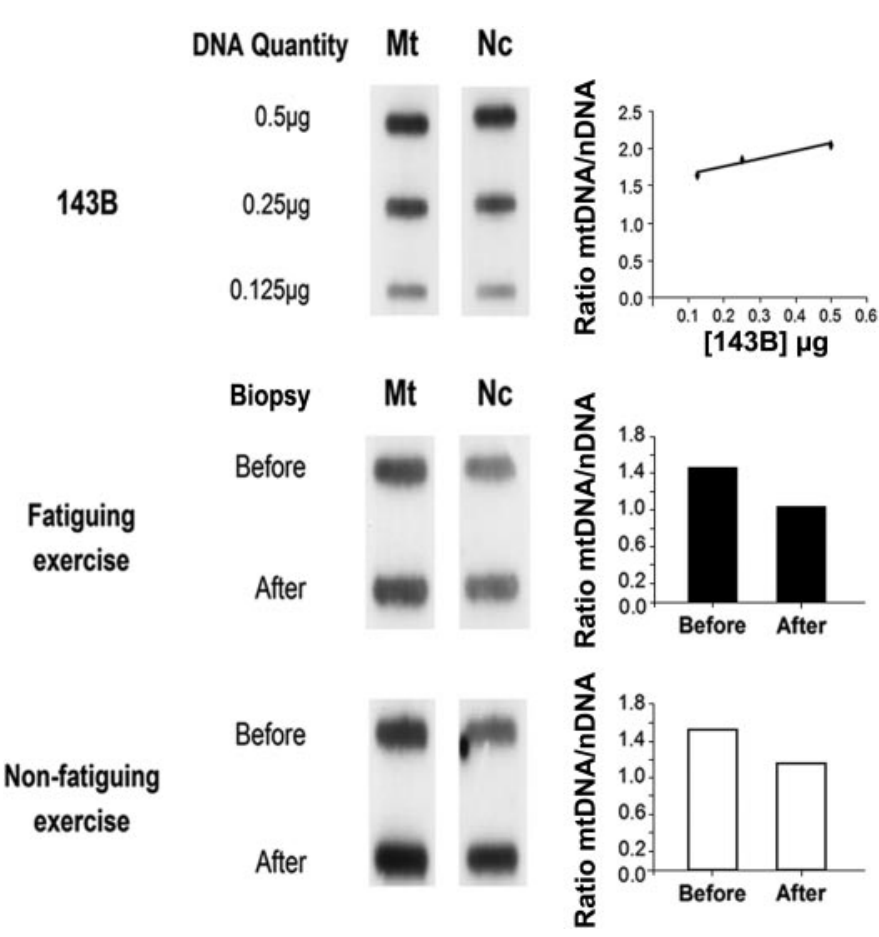

Fig. 1. Autoradiography of 143B and human muscle DNA, detected by slot-blot hybridization with a mitochondrial (Mt) and nuclear (Nc) ribosomal DNA probe. Each slot corresponds to human muscle DNA of different biopsy samples from the same individual, obtained before and after the fatiguing and nonfatiguing prolonged exercise protocols, except for those loaded with 0.5 $\mu \mathrm{g}, 0.25 \mu \mathrm{g}$, or $0.125 \mu \mathrm{g}$ of total DNA from 143B. The 143B is a human osteosarcoma-derived cell line used here as a control to show a correlation between DNA loaded and signal obtained. Because the mitochondrial (mtDNA)-to-nuclear DNA (nDNA) ratio (mtDNA/nDNA) of 143B line cell correlates tightly with total DNA loaded $(y=1.06 x+1.55 ; r=0.972)$, it was assumed that the changes in sample signals reflect proportional changes in mtDNA content. 
System (Applied Biosystems, Foster City, CA). The mtDNA quantity was corrected by simultaneous measurement of a single copy nuclear RNase P gene. The fragment of mtDNA assayed was a 123-bp (807 to 929 ) fragment of $12 \mathrm{~S}$ RNA. The primers used to detect the mtDNA $12 \mathrm{~S}$ sequences were MT-L (5'-CCACGGGAAACAGCAGTGATT$\left.3^{\prime}\right)$ and MT-H (5'-CTATTGACTTGGGTTAATCGTGTGA-3') and were used together with the mtDNA specific fluorescent-type MGB (minor groove binding) Taqman probe, which was labeled internally by the fluorescent dye FAM (5'-TGC CAG CCA CCG CG-3'). Probe and primers designs were performed with Primer Express 2.0 software (Applied Biosystems). To quantify nDNA, a commercial kit was used (PDARs RNAseP; Applied Biosystems), and the nDNA-specific fluorescent probe was labeled internally using the fluorescent dye VIC.

RT-PCR amplification was carried out in a $20-\mu l$ final volume containing $1 \times$ Platinum Quantitative PCR SuperMix-UDG (Invitrogen, Carlsbad, CA), $110 \mathrm{nM}$ of each primer used for mtDNA, $125 \mathrm{nM}$ Taqman probe, 10-15 ng DNA total, $1 \times$ PDARs RNAseP kit, and ROX (Invitrogen) used as a reference dye. The thermal cycling conditions were $50^{\circ} \mathrm{C}$ for $2 \mathrm{~min}, 95^{\circ} \mathrm{C}$ for $10 \mathrm{~min}, 40$ cycles of $95^{\circ} \mathrm{C}$ for $15 \mathrm{~s}$, and $60^{\circ} \mathrm{C}$ for $1 \mathrm{~min}$. Tenfold serial dilutions of standard were included in each experiment to generate the standard curve. At least two "no-template controls" were included with each experiment.

Statistical analysis. A one-way (trial-by-time) repeated-measures ANOVA was performed to test significance within treatments. After a significant $F$ test, pairwise differences were identified using Tukey's honestly significant differences post hoc procedure (Sigma Stat packet). The statistical analysis was performed using the data from all the subjects who completed a given experimental protocol.

\section{RESULTS}

Total DNA isolation was carried out with repeated phenol extraction that excludes single-stranded DNA (25). Therefore, only double-stranded DNA (mature mtDNA) could be determined under these conditions. Estimation of mtDNA content was performed by slot-blot hybridization and confirmed by RT-PCR.

In control studies, mtDNA/nDNA, estimated by slot-blot hybridization, did not change either after $2 \mathrm{~h}$ of supine rest $(1.028 \pm 0.126$ vs. $1.133 \pm 0.105$ before and after, respectively; $n=5 ; P=0.223$ ) or after subsequent $2 \mathrm{~h}$ of light exercise $(1.149 \pm 0.205$ vs. $1.133 \pm 0.105 ; P=0.92)$. In contrast, mtDNA/nDNA declined significantly after prolonged fatiguing exercise compared with baseline values $(0.863 \pm$ 0.061 vs. $1.101 \pm 0.067 ; n=14 ; P=0.005$; Fig. $2 A)$, with nine subjects showing a $32 \pm 5 \%$ decline and the remaining subjects showing no decline. Having established that mtDNA/ nDNA drops after prolonged fatiguing exercise, we investigated the recovery time. In a subset of subjects, mtDNA/nDNA remained low after $2 \mathrm{~h}(n=8 ; P=0.043$; one-tailed ANOVA) and $24 \mathrm{~h}(n=5 ; P=0.0945$; one-tailed ANOVA; see Fig. 4) of recovery compared with baseline values. However, mtDNA/ nDNA was restored to baseline values after $1 \mathrm{wk}(1.234 \pm$ 0.103 vs. $1.107 \pm 0.069$ after $1 \mathrm{wk}$ and baseline, respectively; $n=8 ; P=0.35)$. When subjects exercised for the same duration and intensity a week later without experiencing fatigue, mtDNA/nDNA also tended to decline $(1.005 \pm 0.0421$ vs. $1.171 \pm 0.093 ; n=10 ; P=0.083$; Fig. $2 B$ ). During short intense exercise, mtDNA/nDNA also declined significantly after three repeated exercise bouts compared with the initial baseline value $(0.900 \pm 0.049$ vs. $1.067 \pm 0.071$, respectively; $n=7 ; P=0.013$; Fig. $2 C$ ).

To confirm the results obtained by slot-blot hybridization, we also estimated mtDNA content by RT-PCR. We could
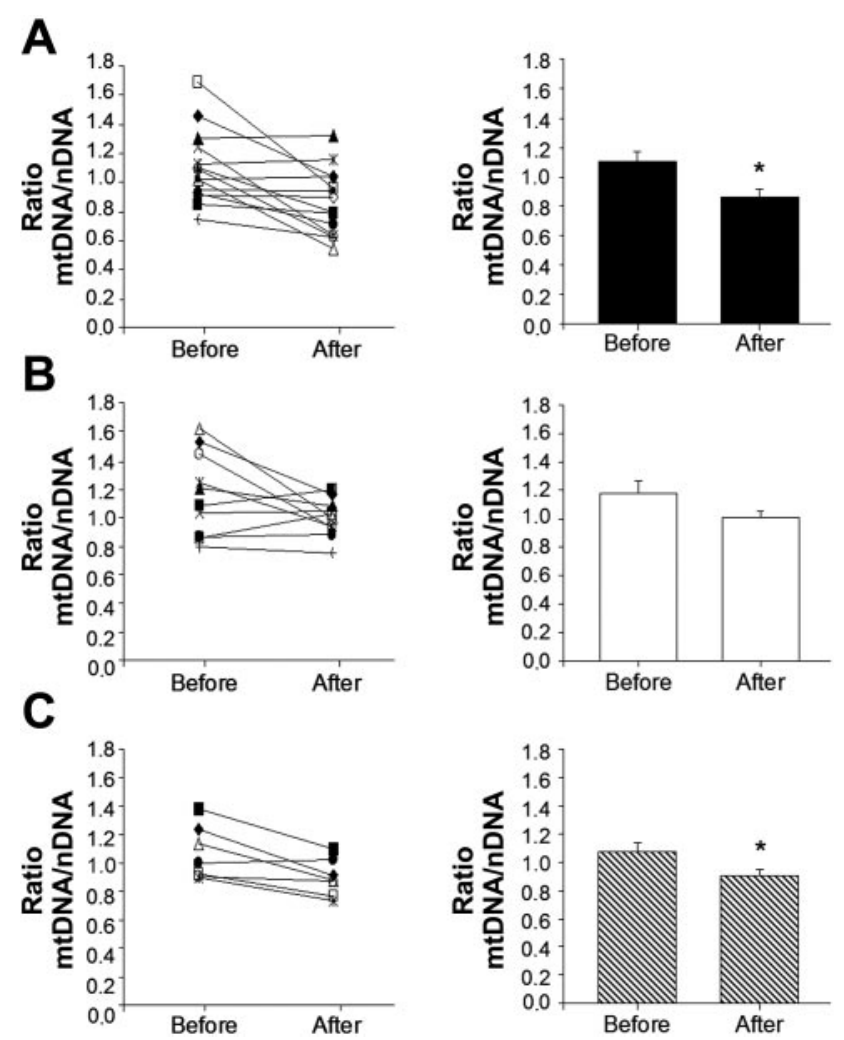

Fig. 2. Effect of prolonged fatiguing and nonfatiguing exercise as well as short high-intensity exercise on skeletal muscle mtDNA content. Points (left) show individual values and bars (right) represent mean $\pm \mathrm{SE}$ mtDNA/nDNA values before and after moderate-intensity fatiguing exercise $(A ; n=14)$, moderateintensity nonfatiguing exercise $(B ; n=10)$, and 3 repeated bouts of heavy exercise $(C ; n=7)$. (See Table 1 for description of experimental protocols.) Note that the reduced mtDNA/nDNA ratio after prolonged fatiguing exercise was restored to baseline levels 1 wk later when subjects came back to exercise for the same duration and intensity without experiencing fatigue (1.234 \pm 0.103 vs. $1.107 \pm 0.069$ before nonfatiguing exercise vs. before fatiguing exercise, respectively; $n=8 ; P=0.35)$. $*$ Significantly lower than values before the prolonged fatiguing exercise $(A ; P=0.005)$ and the 3 repeated high-intensity exercise bouts $(C ; P=0.013)$. After prolonged nonfatiguing exercise, mtDNA/nDNA tended to decline $(B ; P=0.083)$.

confirm the results in all samples, except for the repeated high-intensity exercise (Fig. 3) that could not be determined owing to the lack of muscle sample. In all cases, the fall in mtDNA/nDNA estimated by slot-blot hybridization was validated by RT-PCR.

\section{DISCUSSION}

We presently investigated whether exercise of different duration and intensity modifies mature mtDNA content of contracting skeletal muscle in healthy human subjects by examining changes in mtDNA/nDNA. The key findings were 1) mtDNA/nDNA declined significantly after exhausting prolonged moderate-intensity exercise as well as after three short high-intensity exercise bouts and tended to decline during nonfatiguing moderate exercise; 2) mtDNA/nDNA remained unchanged during control resting and light-exercise conditions; 3) some subjects showed marked decreases in mtDNA/nDNA during prolonged, moderate-intensity fatiguing and nonfatiguing exercise whereas others were unresponsive; and 4) mtDNA/nDNA remained low after $24 \mathrm{~h}$ of recovery from 


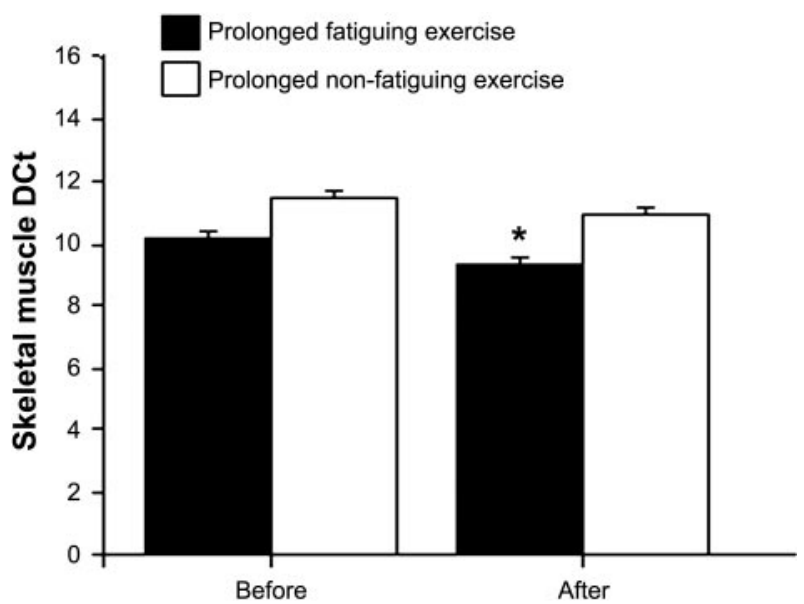

Fig. 3. Effect of prolonged fatiguing and nonfatiguing exercise on skeletal muscle mtDNA content determined by real-time PCR. Variation of cycle number threshold $(\Delta \mathrm{Ct})$ between mtDNA and nDNA before and after exercise was measured in the moderate intensity fatiguing (*statistically significant; $P=0.02)$ and nonfatiguing $(P=0.09)$ exercise bouts. Effect of 3 short repeated high-intensity exercise bouts could not be determined by the lack of sample DNA.

prolonged fatiguing exercise but was fully restored after $1 \mathrm{wk}$. Collectively, these results in healthy humans suggest that prolonged and short repeated intense exercise can lead to marked reductions in exercising skeletal muscle mtDNA content at least in some subjects.

To our knowledge, this is the first description that exercise reduces mtDNA content in human skeletal muscle. There are two possible explanations for this finding. On one hand, the decline in mtDNA content during prolonged moderate-intensity and repeated short high-intensity exercise could be ascribed to an enhanced mitochondrial biogenesis during exercise, which is accompanied by increases in single-stranded DNA molecules not extractable under our experimental conditions. The strong energy demand accompanying prolonged moderate-intensity and heavy-intensity exercise can result in a net decrease in skeletal muscle ATP and PCr and net increase in $\operatorname{ADP}$ and $P_{i}(12,14,16,21,29,35)$. MtDNA replication is an energy-requiring process and is therefore less favored under high ADP concentration as demonstrated by the marked decrease in DNA synthesis in isolated mitochondria when ADP increases (11). It therefore seems unlikely that the present decline in mtDNA with moderate and heavy exercise is associated with an enhanced mitochondrial biogenesis.

Alternatively, a large number of reports indicate that prolonged and intense exercise is associated with increases in skeletal muscle oxidative stress and ROS production, which have the potential to damage mtDNA and increase susceptibility of mitochondrial membrane proton conductance to oxidative stress $(2,4,6,19,20,22,23,26,28,32)$. A large increase in temperature as seen here during prolonged fatiguing and maximal exercise (muscle temperature $\geq 40^{\circ} \mathrm{C}$ ) has also been shown to induce a decrease in mitochondrial coupling and a higher release of ROS (1). Because of the high reactivity of ROS, mtDNA, components of mitochondrial membrane, and different cellular processes including mitochondrial biogenesis are presumably the main targets for ROS in eukaryotic cells (3, 5). In contrast to strenuous exercise, mtDNA remained un- changed after $2 \mathrm{~h}$ of low-intensity exercise $\left(25 \% \mathrm{~V}_{2}\right.$ max $)$; an exercise bout that produces low physiological and oxidative stress. Interestingly, moderate prolonged nonfatiguing exercise with stable muscle temperature and hemodynamic variables tended to reduce mtDNA. This suggests that factors such as high muscle temperature, muscle energy crisis, and stress hormones may contribute to enlarge the lowering of mtDNA but are not responsible for the majority of the response. This interpretation concords with the finding that mtDNA did not decline after the first bout of maximal exercise despite the precipitated fatigue due to heat stress. The lower mtDNA after three repeated bouts of high-intensity exercise might then be the result of cumulative ROS damage.

Although the precise mechanism needs further investigation, these present results indicate that prolonged and short repeated intense exercise can lead to marked reductions in mature mtDNA content of exercising skeletal muscle at least in some subjects. Compelling evidence supports an increase in mitochondrial biogenesis with prolonged endurance training (13, 18). It is therefore possible that mtDNA damage by ROS is a prerequisite for adaptation to training. Endogenous ROS (24) could then enhance the expression of nuclear mitochondrial biogenesis genes as mRNAs measures of nuclear respiratory factor- $1 \alpha$, and mtTFA has been shown to increase after endurance exercise (27). Furthermore, our observations are in agreement with a recent report showing a lesser activity of the putative regulator of muscle protein breakdown nuclear factor- $\mathrm{\kappa B}$ immediately after fatiguing exercise and its restoration after $1 \mathrm{~h}$ recovery, in contrast to the unchanged activity during nonfatiguing exercise (10). Thus it seems that prolonged fatiguing exercise is indeed modifying mtDNA content and nuclear signaling for protein turnover in active skeletal myocytes.

Another interesting observation was that mature mtDNA remained seemingly low after $24 \mathrm{~h}$ of recovery from prolonged fatiguing exercise (Fig. 4), being fully restored after a week (Fig. 2). A limitation of the study is, however, the low number

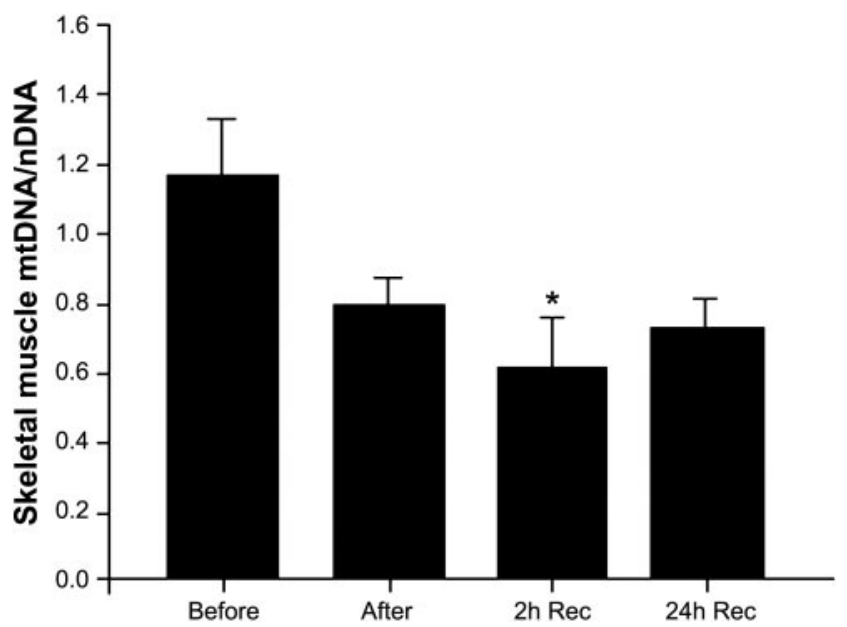

Fig. 4. Effect of prolonged fatiguing exercise and subsequent $24 \mathrm{~h}$ of recovery on mtDNA content in skeletal muscle. Bars show means \pm SE mtDNA/nDNA values before, after $2-2.5 \mathrm{~h}$ of prolonged fatiguing cycling exercise $(n=8)$, and after 2 and $24 \mathrm{~h}$ of recovery $(n=5)$. Muscle biopsy samples at $24 \mathrm{~h}$ of recovery were only obtained in 5 of 8 subjects. The 24 -h recovery vs. before comparison includes only 5 subjects. *Significantly lower than before, $P<0.05$. 
of subjects that could undergo the highly demanding exercise protocols and the additional biopsy samples during the recovery process. The present lack of statistical significance in the recovery after a 24-h period in five subjects may therefore reflect a type II error due to insufficient statistical power because a significant difference for a lower $\mathrm{mtDNA} / \mathrm{nDNA}$ was observed after $2 \mathrm{~h}$ of recovery in eight subjects $(P=0.043)$. Moreover, even though our study does not provide direct mtDNA data from day 2 to day 6 into the recovery, it is likely that mtDNA content was restored to baseline values before a week considering that these trained subjects could resume their regular training 2 days after the experiment. Future studies should provide more detailed information about the time course for the recovery of skeletal muscle mtDNA content.

The differences in the magnitude of response among subjects during the prolonged fatiguing trial, with the majority of subjects showing a large decline but five subjects showing no change $\mathrm{mtDNA} / \mathrm{nDNA}$, could reflect genetic differences in coping with similar levels of hyperthermic, metabolic, and circulatory stress (15). Similarly, genetic singularities as well as different antioxidant capacity among subjects might explain the observation that five subjects still showed a $26 \pm 5 \%$ decline in mtDNA/nDNA but others showed no change when physiological homeostasis was apparently maintained over the 2- to 2.5 -h exercise bout by ingesting large volumes of fluid during exercise $(14,15)$. Thus it remains to be clarified whether harder exercise conditions would be required to induce the same decline to skeletal muscle mature mtDNA content in different subjects.

In summary, these findings showed that, in contrast to the unchanged response during resting and light exercise conditions, mature mtDNA declines significantly after a bout of exhausting prolonged moderate-intensity exercise and after three bouts of short high-intensity exercise, remaining apparently reduced for at least $24 \mathrm{~h}$. We propose that the known enhancement of mitochondrial biogenesis with exercise training could be an adaptive response to the mtDNA decline evoked by an intense training session consisting of a single bout of prolonged moderate-intensity exercise or several bouts of heavy-intensity exercise.

\section{ACKNOWLEDGMENTS}

We thank S. Morales for technical assistance.

\section{GRANTS}

This work was supported by the Gatorade Sports Science Institute, the High Sport Council (06/UPB/03) (Spain), the Government of Aragón (Consolidated Groups B33), and Spanish Network for Mitochondria Disorders (G03-011). J. González-Alonso is supported by The Copenhagen Hospital System.

\section{REFERENCES}

1. Abele D, Heise K, Portner HO, and Puntarulo S. Temperature-dependence of mitochondrial function and production of reactive oxygen species in the intertidal mud clam Mya arenaria. J Exp Biol 205: 1831-1841, 2002.

2. Bejma J, Ramires $\mathbf{P}$, and Ji LL. Free radical generation and oxidative stress with ageing and exercise: differential effects in the myocardium and liver. Acta Physiol Scand 169: 343-351, 2000.

3. Chandwaney R, Leichtweis S, Leeuwenburgh C, and Ji L. Oxidative stress and mitochondrial function in skeletal muscle: effects of aging and exercise training. Age 21: 109-117, 1998.

4. Cooper CE, Vollaard NB, Choueiri T, and Wilson MT. Exercise, free radicals and oxidative stress. Biochem Soc Trans 30: 280-285, 2002.

5. Davies KJ, Quintanilha AT, Brooks GA, and Packer L. Free radicals and tissue damage produced by exercise. Biochem Biophys Res Commun 107: $1198-1205,1982$.
6. Di Meo S and Venditti P. Mitochondria in exercise-induced oxidative stress. Biol Signals Recept 10: 125-140, 2001.

7. Diez-Sanchez C, Ruiz-Pesini E, Lapena AC, Montoya J, Perez-Martos A, Enriquez JA, and Lopez-Perez MJ. Mitochondrial DNA content of human spermatozoa. Biol Reprod 68: 180-185, 2003.

8. DiMauro $\mathbf{S}$ and Andreu AL. Mutations in mitochondrial DNA as a cause of exercise intolerance. Ann Med 33: 472-476, 2001.

9. DiMauro $\mathbf{S}$ and Schon EA. Mitochondrial respiratory-chain diseases. N Engl J Med 348: 2656-2668, 2003.

10. Durham WJ, Li YP, Gerken E, Farid M, Arbogast S, Wolfe RR, and Reid MB. Fatiguing exercise reduces DNA binding activity of NF- $\mathrm{KB}$ in skeletal muscle nuclei. J Appl Physiol 97: 1740-1745, 2004.

11. Enriquez JA, Ramos J, Perez-Martos A, Lopez-Perez MJ, and Montoya J. Highly efficient DNA synthesis in isolated mitochondria from rat liver. Nucleic Acids Res 22: 1861-1865, 1994.

12. Fenning A, Harrison G, Dwyer D, Rose'Meyer R, and Brown L. Cardiac adaptation to endurance exercise in rats. Mol Cell Biochem 251: 51-59, 2003.

13. Freyssenet D, Berthon P, and Denis C. Mitochondrial biogenesis in skeletal muscle in response to endurance exercises. Arch Physiol Biochem 104: 129-141, 1996.

14. Gonzalez-Alonso J and Calbet JA. Reductions in systemic and skeletal muscle blood flow and oxygen delivery limit maximal aerobic capacity in humans. Circulation 107: 824-830, 2003.

15. Gonzalez-Alonso J, Calbet JA, and Nielsen B. Metabolic and thermodynamic responses to dehydration-induced reductions in muscle blood flow in exercising humans. J Physiol 520: 577-589, 1999.

16. Gonzalez-Alonso J, Quistorff B, Krustrup P, Bangsbo J, and Saltin B. Heat production in human skeletal muscle at the onset of intense dynamic exercise. J Physiol 524: 603-615, 2000.

17. Hoppeler H, Luthi P, Claassen H, Weibel ER, and Howald H. The ultrastructure of the normal human skeletal muscle. A morphometric analysis on untrained men, women and well-trained orienteers. Pflügers Arch 344: 217-232, 1973.

18. Irrcher I, Adhihetty PJ, Joseph AM, Ljubicic V, and Hood DA. Regulation of mitochondrial biogenesis in muscle by endurance exercise. Sports Med 33: 783-793, 2003.

19. Ji LL. Antioxidants and oxidative stress in exercise. Proc Soc Exp Biol Med 222: 283-292, 1999.

20. Ji LL. Oxidative stress during exercise: implication of antioxidant nutrients. Free Radic Biol Med 18: 1079-1086, 1995.

21. Krause $\mathbf{U}$ and Wegener G. Exercise and recovery in frog muscle: metabolism of PCr, adenine nucleotides, and related compounds. Am J Physiol Regul Integr Comp Physiol 270: R811-R820, 1996.

22. Leeuwenburgh $\mathbf{C}$ and Heinecke $\mathbf{J W}$. Oxidative stress and antioxidants in exercise. Curr Med Chem 8: 829-838, 2001.

23. Liu J, Yeo HC, Overvik-Douki E, Hagen T, Doniger SJ, Chyu DW, Brooks GA, Ames BN, and Chu DW. Chronically and acutely exercised rats: biomarkers of oxidative stress and endogenous antioxidants. J Appl Physiol 89: 21-28, 2000.

24. Miranda S, Foncea R, Guerrero J, and Leighton F. Oxidative stress and upregulation of mitochondrial biogenesis genes in mitochondrial DNAdepleted HeLa cells. Biochem Biophys Res Commun 258: 44-49, 1999.

25. Morris SR and Shertzer HG. Rapid analysis of DNA strand breaks in soft tissues. Environ Mutagen 7: 871-880, 1985.

26. Navarro A, Gomez C, Lopez-Cepero JM, and Boveris A. Beneficial effects of moderate exercise on mice aging: survival, behavior, oxidative stress and mitochondrial electron transfer. Am J Physiol Regul Integr Comp Physiol 286: R505-R511, 2004.

27. Pilegaard H, Saltin B, and Neufer PD. Exercise induces transient transcriptional activation of the PGC-1alpha gene in human skeletal muscle. J Physiol 546: 851-858, 2003.

28. Poulsen HE, Loft $\mathbf{S}$, and Vistisen K. Extreme exercise and oxidative DNA modification. J Sports Sci 14: 343-346, 1996.

29. Sahlin K, Soderlund K, Tonkonogi M, and Hirakoba K. Phosphocreatine content in single fibers of human muscle after sustained submaximal exercise. Am J Physiol Cell Physiol 273: C172-C178, 1997.

30. Sambrook J, Fristch EF, and Maniatis T. Molecular Cloning: A Laboratory Manual. Cold Spring Harbor, New York: Cold Spring Harbor Laboratory Press, 1989.

31. Solano A, Gamez J, Carod FJ, Pineda M, Playan A, Lopez-Gallardo E, Andreu AL, and Montoya J. Characterisation of repeat and palindrome elements in patients harbouring single deletions of mitochondrial 
DNA. J Med Genet 40: e86, 2003. (http://www.jmedgenet.com/cgi/content/ full/40/7/e86).

32. Tonkonogi M, Walsh B, Svensson M, and Sahlin K. Mitochondrial function and antioxidative defence in human muscle: effects of endurance training and oxidative stress. J Physiol 528: 379-388, 2000.

33. Von Kleist-Retzow JC, Schauseil-Zipf U, Michalk DV, and Kunz WS. Mitochondrial diseases - an expanding spectrum of disorders and affected genes. Exp Physiol 88: 155-166, 2003.
34. Wang H, Hiatt WR, Barstow TJ, and Brass EP. Relationships between muscle mitochondrial DNA content, mitochondrial enzyme activity and oxidative capacity in man: alterations with disease. Eur J Appl Physiol 80: 22-27, 1999.

35. Weicker H, Hageloch W, Luo J, Muller D, Werle E, and Sehling KM. Purine nucleotides and AMP deamination during maximal and endurance swimming exercise in heart and skeletal muscle of rats. Int J Sports Med 11, Suppl 2: S68-S77, 1990.

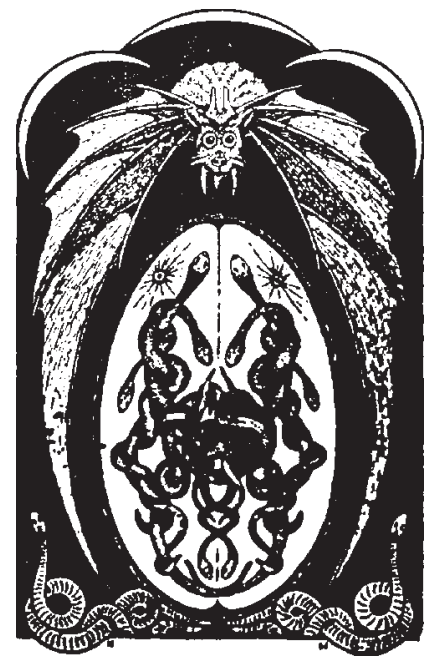

